\title{
Valêncio Xavier: Fotografando a Morte
}

\section{Pascoal Farinaccio, UFF}

Resumo: Este artigo aborda relações entre fotografia, morte e lembrança. Para situar essa reflexão no contexto atual dos meios de comunicação de massa realiza-se aqui a análise crítica do texto de ficção "Rremembranças da menina de rua morta nua", obra de Valêncio Xavier, caracterizada formalmente pelo uso simultâneo de palavras e imagens.

Palavras-chave: fotografia; meios de comunicação de massa; Valêncio Xavier

\section{Fotografia, Morte e Lembrança}

A íntima relação existente entre fotografia e morte foi observada por vários críticos. Susan Sontag, por exemplo, escreve em Sobre Fotografia: "As fotos declaram a inocência, a vulnerabilidade de vidas que rumam para a própria destruição, e esse vínculo entre fotografia e morte assombra todas as fotos de pessoas". ${ }^{1}$ Notoriamente, as fotografias registram a passagem do tempo na vida das pessoas e necessariamente o envelhecimento e a aproximação inevitável da morte. Toda foto é um memento mori, portanto.

Numa concepção mais ampla, Barthes, em estudo hoje clássico, dirá desta coisa "um pouco terrível que há em toda foto: o retorno do morto". ${ }^{2}$ Toda imagem fotográfica opera o "retorno do morto", traz para o presente da sua recepção o tempo e o espaço do passado. Quando olhamos uma foto, necessariamente vemos o que já se passou; daí Barthes afirmar que toda foto é um "isso foi". Nessa perspectiva, chega a aproximar a arte fotográfica da arte teatral primitiva, remetendo à relação original do teatro com o "culto dos mortos" - nas fotos, segundo o autor, vemos sempre os mortos.

Um exemplo literalmente concreto dessa relação entre fotografia e morte é o antigo costume de fotografar entes queridos falecidos para guardar como uma última lembrança. Isso ocorria em meados do século XIX e certamente alcançou as duas primeiras décadas do século XX. Boris Kossoy, em sua obra historiográfica Origens e Expansão da Fotografia no Brasil - Século $X I X$, observa que se tratava de costume bastante difundido e arraigado, de tal maneira que muitos fotógrafos anunciavam em jornais o serviço domiciliar de fotografar os mortos:

Em 1854 Cincinato Mavignier, no Recife, propunha-se “a fazer os retratos das pessoas fallecidas, indo com a machina até a casa de quem quizer possuir a verdadeira semilhança do objecto finado" [...] ou mesmo a elegante Photographie Française de Labadie que anunciava em 1881 tirar "retratos a domicilio de defuntos, doentes etc". 3

Essa relação por assim dizer "pragmática" da fotografia com relação aos mortos encontra sua razão de ser na natureza profunda da própria fotografia. 
Como observa Kossoy, ao capturar e preservar um instante da vida, a fotografia ao mesmo tempo congela "um instante de morte, pois o elemento vivido é irreversível". Justamente nessa perspectiva, o autor cita uma frase célebre atribuída a Oscar Wilde, que faz a associação entre fotografia e morte de maneira radical: "Não se deveria fotografar senão aos mortos; a fotografia é o exato reflexo da morte". ${ }^{4}$

Se se relaciona de forma íntima com a morte, a fotografia, por outro lado, também está vinculada à exigência da lembrança. Em um belo e denso texto sobre fotografia, notoriamente de inspiração benjaminiana, Giorgio Agambem nos fala dessa exigência:

Há porém outro aspecto nas fotografias que amo, que não gostaria de silenciar de modo algum. Trata-se de uma exigência: o sujeito fotografado exige algo de nós. Prezo especialmente o conceito de exigência, que não deve ser confundido com uma necessidade factual. Mesmo que a pessoa fotografada fosse hoje completamente esquecida, mesmo que seu nome fosse apagado para sempre da memória dos homens, mesmo assim, apesar disso - ou melhor, precisamente por isso - aquela pessoa, aquele rosto exigem o seu nome, exigem que não sejam esquecidos. ${ }^{5}$

Para Agamben trata-se precisamente de uma "exigência de redenção": a fotografia "capta o real que está sempre no ato de se perder para torná-lo novamente possível". 6 O "anjo da fotografia", diz, "exige que nos recordemos", que sejamos fieis "testemunhas de todos os nomes perdidos". Justamente nessa perspectiva, pode-se pensar a fotografia - e eis aqui a mais bela definição de fotografia de que temos conhecimento - como algo que se encontra entre "a lembrança e a esperança".

Agamben utiliza a expressão "anjo da fotografia" e, vale lembrar aqui que o mais famoso anjo na obra de Walter Benjamin, o "anjo da história”, cuja formulação parte de um quadro de Klee, contempla as ruínas do passado desejoso justamente de "acordar os mortos e juntar os destroços". Em notável ensaio sobre as figuras dos anjos na obra do filósofo alemão, Jeanne Marie Gagnebin observa que o que todos os "anjos de Benjamin, sem exceção, desejam profundamente, é a felicidade; essa não é nem a volta a um paraíso de antes da história, nem tampouco a avidez devoradora da modernidade, sempre em busca de novidades". Trata-se de uma "temporalidade feliz", "tensão de um tempo simultaneamente sempre novo e sempre retomado" - temporalidade que pode, a nosso ver e tendo em vista a reflexão que nos interessa diretamente, ser aproximado da felicidade de retomada do passado no presente da recepção de nossas fotografias preferidas.

Em sua "Crônica de Berlim", Walter Benjamin faz uma aproximação entre os mecanismos da memória e a fotografia. Inicialmente, observa que "a felicidade que eu recordo vem acompanhada de outra felicidade, a de poder recordá-la". Em seguida prossegue com observações sobre a revelação mnemônica que se pode dar na "placa da recordação": 
Todos podem dar-se conta de que a duração de nossas impressões se encontra na recordação sem motivos claros. Nada nos impede, por exemplo, ter a recordação mais ou menos clara de alguns lugares nos quais só passamos vinte e quatro horas, enquanto que outros onde estivemos durante meses caíram no olvido mais absoluto. Nem sempre é questão, portanto, de um tempo de exposição demasiado curto que na placa da recordação não apareça nenhuma fotografia. São muito mais habituais os casos em que a luz débil do costume nega à placa a luminosidade que necessita, até que esta brota num bom dia de fontes estranhas como de um pó de magnésio incendiado e retém magicamente na placa a figura de uma tomada instantânea. ${ }^{9}$

Como em outras reflexões de Benjamin em torno da rememoração do passado, o que está em jogo aí é uma espécie de figura temporal de redenção daquilo que foi: uma rememoração que não é simplesmente restauração do passado, mas também transformação do presente a partir da irrupção do passado no presente e da nova constelação assim formada. Não se trata nunca de simples retorno, mas do "estabelecimento de uma nova ligação entre o passado e o presente". ${ }^{10}$ Essa delicada possibilidade de uma nova ligação não está de forma alguma assegurada - realmente, é preciso de um "bom dia" para que a luminosidade eficaz se faça.

\section{Valêncio Xavier e a menina de rua aqui e agora}

O texto de Valêncio Xavier, Rremembranças da Menina de Rua Morta Nua, que faz largo uso de imagens fotográficas, parece configurar um esforço que se equilibra precisamente entre "a lembrança e a esperança" numa tentativa de redenção de um destino humano. Atualiza uma notável reflexão ficcional sobre a morte e o tratamento sensacionalista que se dá ao assunto na imprensa brasileira. Como procuraremos demonstrar através da análise da obra, a abordagem dos mass media, movida pelo desejo de audiência, espetaculariza o evento da morte e leva morte a morte: inflacionaa na redundância de representações imagéticas e escritas, que se tornam essencialmente descartáveis e destinadas ao rápido esquecimento. A morte como entretenimento para as massas, como show, implica a destruição da memória do morto. Digamos que a deriva da obra de Xavier pega o caminho contrário, expõe o substrato ideológico do interesse das mídias e aponta para outras formas de tratamento do assunto.

Com efeito, "Rremembranças" não se basta em denunciar o sensacionalismo, à vista de todos, mas elabora uma reflexão sobre a questão da memória, ao mesmo tempo em que ridiculariza - com muito humor, digase - as estratégias comerciais da televisão no contexto contemporâneo. Essa reflexão se articula formalmente mediante o atrito de linguagens diversas, realizada com a maestria de um escritor que sabe como ninguém colocar em diálogo letras e imagens.

O recurso formal básico na construção de seu texto é a colagem. O autor cola materiais diversos nas páginas de seu livro, inaugurando relações novas entre eles. Uma dessas relações, em especial, tem um efeito crítico notável 
no que se refere à questão da memória, como veremos mais adiante. $\mathrm{O}$ procedimento desloca tais materiais de seus contextos de origem, recontextualizando-os na configuração original, única e irrepetível gerada pela obra. A significação de cada um desses fragmentos muda substancialmente em função do conjunto no qual são inseridos e passam a operar. No caso de "Rremembranças", a significação ganha força mediante o atrito de materiais estética e ideologicamente diferenciados, a que se deve somar também a distância histórica das fontes de origem.

A primeira página do texto é uma ilustração retirada do "Caderno TV" do Jornal do Brasil de 27 de março de 1993, conforme se informa nos créditos finais. A ilustração diz respeito ao programa televisivo Aqui Agora, que era exibido diariamente pelo SBT nos anos 1990. Para proveito de nossa análise reproduzimos a imagem:

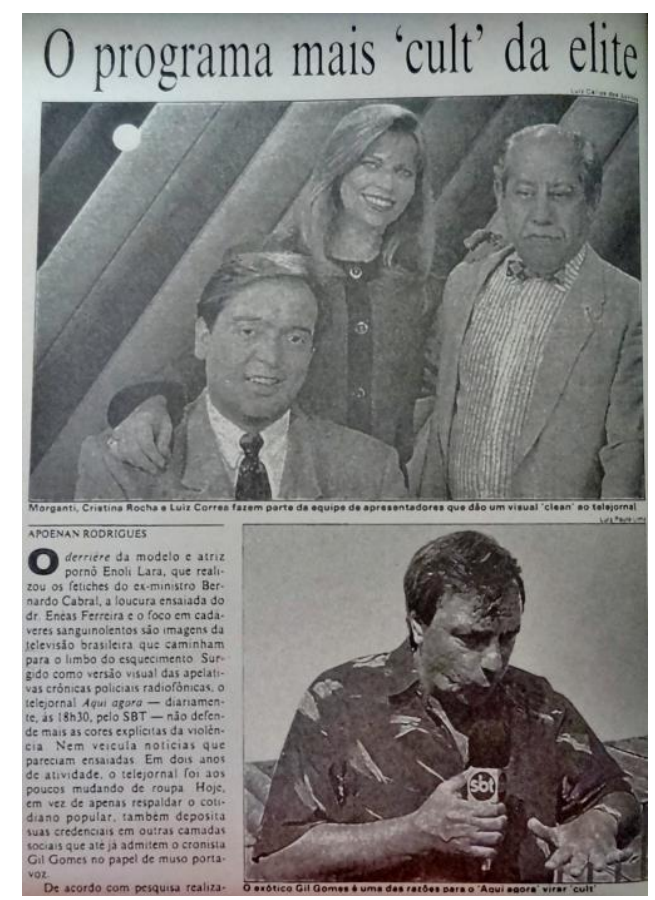

Fig. $1^{11}$

O Aqui e Agora abordava principalmente casos policiais e de violência urbana, mas de uma forma a que nunca faltava certo humor. Seus âncoras e repórteres sempre tinham algo de excêntrico no modo de falar, de vestir-se e de se comportar. Gil Gomes, que aparece sozinho na ilustração, era possivelmente aquele que alcançava maior sucesso de público: tinha uma dicção muito própria de narrar os casos policiais, imprimindo-lhes sempre algo de mistério e suspense, trazendo para a mídia televisiva a sua experiência como comentarista policial no rádio. Acrescente-se à dicção 
excêntrica algo que desenvolveu especificamente para a TV: um modo singular de movimentar as mãos em pequenos círculos enquanto falava. Em suma, temos aqui uma personagem com apurada consciência dos efeitos midiáticos passíveis de serem mobilizados de maneira impactante em seu trabalho nos meios de comunicação.

O Aqui Agora era sem dúvida um programa de gosto extremamente duvidoso. Do ponto de vista comercial, era proposto como "popular", entendendo-se o termo em seu sentido mais grosseiro e preconceituoso: um programa rebaixado ao nível dos que supostamente não possuem refinamento cultural e tampouco maiores recursos financeiros (embora não deixasse de ser visto pelas nossas "elites", como sugere a reportagem do Jornal do Brasil). Em todo caso, alcançou à época grande êxito de público. A ilustração utilizada por Xavier toca no assunto central de "Rremenbranças": a questão da memória. Como se pode ler no jornal: "O derrière da modelo e atriz pornô Enoli Lara, que realizou os fetiches do exministro Bernardo Cabral, a loucura ensaiada do dr. Enéas Ferreira e o foco em cadáveres sanguinolentos são imagens da televisão brasileira que caminham para o limbo do esquecimento". E aqui já há um ponto interessante a destacarmos: Xavier se vale de materiais da imprensa para operacionalizar sua crítica à destruição da memória conforme praticada pela própria imprensa.

A página seguinte do texto coloca Gil Gomes e o próprio Valêncio Xavier como personagens da trama:

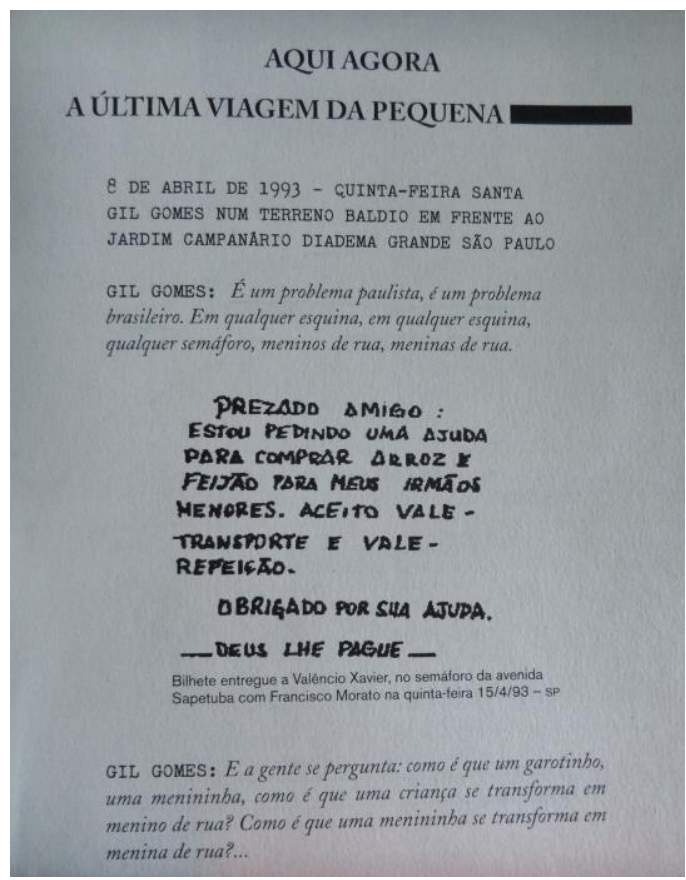

Fig. $2^{12}$ 
Uma página que cola materiais diversos, os quais possuem, no entanto, fortes relações de proximidade semântica. Lemos (ou melhor, ouvimos... e na dicção excêntrica referida, caso a conheçamos de experiência próxima, como é o nosso caso) Gil Gomes noticiando no programa Aqui Agora o assassinato da menina de rua. No centro da página, um bilhetinho do tipo que é geralmente entregue por pessoas em situação financeira precária nos transportes públicos ou semáforos, solicitando algum dinheiro a passageiros e passantes. Quem recebe o bilhete é o próprio Valêncio Xavier, conforme indica a legenda. Assim, o autor, referido pelo nome próprio, transforma-se em personagem de sua própria obra. Mais à frente, percebemos que Valêncio está assistindo ao programa Aqui Agora, mas com distanciamento crítico e postura irônica. Assim, ao ouvir Gil Gomes falando sobre o trem-fantasma do parque de diversões em que a menina foi encontrada morta, retruca: "Trem-fantasma coisa nenhuma. O Mundo do Terror é um barracão bem vagabundinho, de tábuas desencontradas, coberto de lona e dentro dele não tem nenhum trem-fantasma. V.X.". ${ }^{13}$ Cria-se uma polifonia em que algumas vozes contraditam outras.

Como em outras obras de Valêncio, o diálogo e atrito entre linguagens diversas, texto e imagem, é o princípio construtivo básico em "Rremembranças". Como em outras de suas realizações, patenteia-se a apropriação criativa das imagens, que se tornam parte estrutural da obra, tão importantes quanto as palavras. Isto é, em suas obras, as imagens nunca funcionam como meras "ilustrações" daquilo que está registrado por escrito. Não há, portanto, redundância entre as informações verbais e imagéticas. Corte-se uma palavra, e mutila-se a obra do autor; corte-se uma imagem, e igualmente teremos irremediavelmente mutilado sua criação.

A interrelação de texto e imagem, conforme realizada, também produz outro efeito de sentido notável do ponto de vista da recepção: temos a impressão, ao ler a obra, de que estamos ao mesmo tempo assistindo a um programa televisivo. Lemos materiais de origens diversas, como recortes de jornais, trechos de poemas, verbetes de dicionários e "assistimos" ao Aqui e Agora quase que simultaneamente. Efeito muito semelhante ao alcançado por Valêncio em "Maciste no Inferno", obra anterior na qual temos a sensação de estarmos lendo uma história e ao mesmo tempo assistindo a um filme: aquele que o personagem principal também vê em um cinema de Curitiba, cujas imagens vão sendo apresentadas intercaladas à sua narrativa focada na tentativa de bulinar uma mulher desconhecida na sala de projeção. ${ }^{14}$

Vejamos mais uma página de "Rremembranças" centrada na representação da mídia televisiva: 


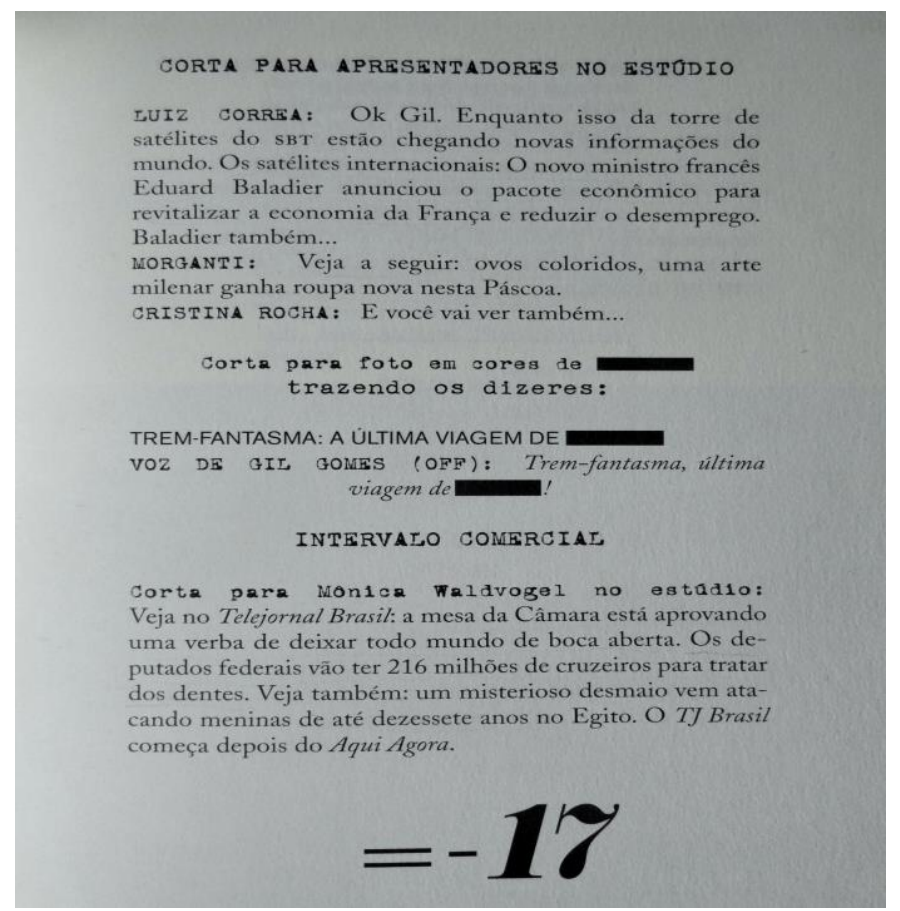

Fig. $3^{15}$

Cabe notar que em "Rremembranças" o assunto em si mesmo já favorece o rápido esquecimento. O assassinato de uma menina de rua, encontrada morta e estuprada dentro de um caixão de trem-fantasma no parque de diversão "O Mundo do Terror", em Diadema-SP. Observe-se desde logo que a menina jamais recebe nome próprio. É sempre e tão-somente a "menina de rua". Expressão que no Brasil é utilizada em estatísticas: tantos meninos de rua vivem nas grandes cidades brasileiras, tantos meninos de rua foram assassinados etc. Meninos e meninas de rua são, por definição, crianças sem história singular. Na mídia, fazem parte da generalização estatística.

Gil Gomes é quem cobre o caso para o Aqui Agora. Ele movimenta-se o tempo todo: vai à Febem, onde a menina costumava almoçar diariamente, entrevista a mãe da menina, e um empregado do parque de diversões. A história da mãe de menina de rua é um exemplo típico, bem brasileiro, de desestruturação familiar e pobreza extrema. Expulsa de casa ainda adolescente pelo pai, pelo motivo de ter feito sexo com um rapaz, parte para uma vida de muitas dificuldades, envolvendo-se com o tráfico de drogas e terminando na prisão, onde Gil Gomes a entrevista. Já o pai da menina teria sido morto por justiceiros. Drogas, pobreza, violência. Os dados nos são apresentados superficialmente e tem tamanha carga de dejà vu que não favorecem a compreensão de seu caráter único (já que a história de cada pessoa é em fím de contas única e irrepetível). Mais uma vez, a abordagem constrói um objeto genérico, que se presta melhor às estatísticas do que à lembrança de sua singularidade. 
A própria fotografia da menina (que o autor pilhou da Agência Estado) tem algo de esquemático e genérico, não favorecendo a cristalização da imagem de uma pessoa singular:

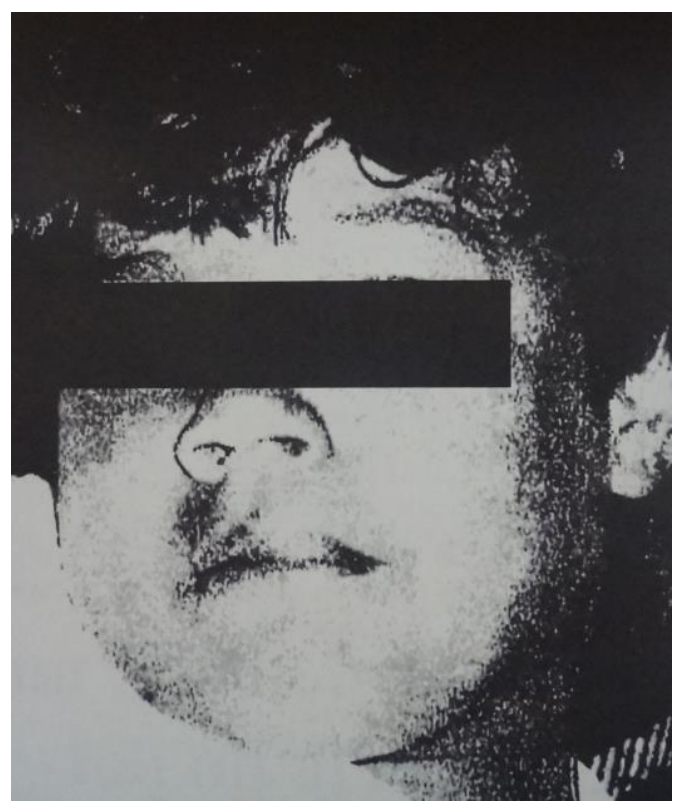

Fig. $4^{16}$

Por fim, some-se a esse desapreço pela história pessoal a mais completa falta de cuidado com as informações repassadas ao público que acompanha o caso de assassinato. Valêncio Xavier cola páginas de jornal noticiando a morte da menina, sendo que uma delas, por exemplo, diz que a menina tem 8 $\operatorname{anos}^{17}$, já outra, $9 \operatorname{anos}^{18}$. Pode-se interpretar isso, sem dúvida, como resultado da competição entre os meios de comunicação de massa, que, ávidos para darem cada qual a notícia antes dos concorrentes, muitas vezes não se dão ao trabalho de averiguar as informações com a atenção necessária.

No caso da nossa menina de rua tudo contribui, portanto, para que a sua trágica história seja rapidamente escoada pelo ralo do esquecimento. Essa história se presta, na melhor das hipóteses, a render alguns pontos de audiência na TV ou a vender alguns jornais, já que envolve assassinato e estupro (em um parque não à toa chamado "Mundo do Terror"). Temas violentos que se encaixam perfeitamente em abordagens midiáticas com tendência sensacionalista ou que exploram o chamado "mundo cão", geralmente com grande sucesso de público.

Como dito anteriormente, entretanto, muito da força crítica desta "Rremembranças" nasce da tensão estabelecida entre linguagens diversas. Assim, após mais uma intervenção de Gil Gomes - "A história dessa menina que você vê agora..." - entra uma colagem inusitada: um verbete do 
Dicionário Etymológico da Língua Portuguesa de José Pedro Machado. Dáse o significado justamente do verbo

lembrar: Do lat. memorare, <lembrar, contar, mencionar; fazer menção de, falar a respeito de; lembrar que>. Houve as fases intermediárias: membrar e nembrar 1. Da primeira, que parece terse arcaizado cedo, só conheço esta abonação do século XVIII: <e, pero era menyno, / rremembra-me que foi assi>, Afonso $\mathrm{X}$, o Sábio...” 19

"Rremembranças" propõe uma extraordinária reflexão sobre a memória na contemporaneidade. Grande parte do texto remete essa reflexão ao problema específico das mídias impressa e televisiva, com destaque para a última. Outros materiais, todavia, são usados por Xavier para criar um contraponto discursivo. $\mathrm{O}$ verbete do dicionário acima citado é um excelente exemplo, e não é à toa que se trata do verbo "lembrar". Através do verbete compreendemos a grafia "rremembranças", que está no título da obra e que causa uma estranheza imediata dada sua verberação arcaizante. Ao utilizá-la em seu título o autor remete tal palavra à história da língua portuguesa. Ou seja, é desde o título que as questões da memória, da rememoração e da história entram em cena.

Páginas adiante outra inserção inusitada de Xavier, de certa maneira ainda mais surpreendente. Há uma nova fala de Gil Gomes diretamente do parque de diversões:

Quem teria matado...? Aparentemente um local de diversão, de brinquedo. Mas agora é a Casa do Terror, e do terror mesmo. E, por enquanto, tudo é mistério [...] O medo virou medo de verdade. A morte da menininha de Diadema...

Após a fala de Gil, uma citação de Os Lusíadas!:

a
morte
escura
longo
tempo
chorando
memorerão
Camões, Lusíadas, III, $135^{20}$

Em princípio a citação pode parecer um pouco obscura, inclusive porque é apenas um fragmento mínimo de uma estrofe. Se formos a Os Lusíadas, veremos que a passagem diz respeito à morte de Inês de Castro e à questão de sua memória. Leia-se a estrofe 135 do canto terceiro na íntegra:

As filhas do Mondego a morte escura

Longo tempo chorando memoraram, 


\section{E, por memória eterna, em fonte pura \\ As lágrimas choradas transformaram; \\ O nome lhe puseram, que inda dura, \\ "Dos amores de Inês", que ali passaram. \\ Vede que fresca fonte rega as flores, \\ Que lágrimas são a água,e o nome Amores! ${ }^{21}$}

As ninfas do Mondego longo tempo "memoraram" Inês e por fim transformaram suas próprias lágrimas em "fonte pura": para a memória eterna de Inês. Notoriamente, contrapõe-se aqui a descartabilidade do discurso televisivo, que noticia ao mesmo tempo em que condena ao esquecimento a morte da menina de rua ao procedimento referido em Os Lusíadas, que diz da perdurabilidade possível da memória. A propósito, poderíamos incluir o próprio Os Lusíadas, publicado pela primeira vez em 1572, como exemplo de um discurso que resiste ao desgaste do tempo. A literatura, em face da rápida obsolescência que caracteriza os produtos do pensamento contemporâneo (discursos midiáticos ou relativos à tecnologia computacional, por exemplo) marca uma diferença, uma dimensão intrínseca de resistência ao envelhecimento precoce. Nessa perspectiva, a literatura de qualidade pode funcionar como uma memória cultural, trazendo o passado nela referido ao nosso presente. Artista sensível à questão contemporânea da imagem, Xavier coloca a literatura para dialogar com discursos audiovisuais, no caso criando um contraponto crítico.

Poderíamos dizer que o texto do escritor produz um efeito verossímil de ruído. Trata-se, no geral, de um texto barulhento. Gil Gomes falando o tempo todo, o entrechoque de notícias contraditórias, o excesso ou bombardeamento de informes televisivos os mais disparatados. Por assim dizer, mal sobra tempo para que respiremos, tomemos consciências das coisas. Bem a propósito, gostaríamos de lembrar, a esta altura, a intuição do escritor argentino Ricardo Piglia, elaborada a partir de sua reflexão sobre as peças para piano do compositor argentino Gerardo Gandini: "[...] os músicos contemporâneos comprovam e dizem o que ninguém sabe: que a cultura de massa não é uma cultura da imagem, mas do ruído". ${ }^{22}$ Pois é justamente essa "cultura do ruído" que Xavier mimetiza com extrema habilidade em "Rremembranças". Uma cultura que tende a destruir os laços sociais constituídos a partir do que poderíamos chamar, tendo em vista o nosso objeto de estudo, de uma adesão solidária à memória dos mortos. Uma cultura, pois, do ruído e também do esquecimento.

Ainda nessa perspectiva, poderíamos pensar na surpreendente referência ao clássico literário português como um lembrete da literatura como um silêncio que se opõe à ruidosa fala contemporânea. Como diz Blanchot em "Morte do Último Escritor": "Um escritor é aquele que impõe silêncio a essa fala, e uma obra literária é, para quem sabe nela penetrar, um lugar rico de silêncio, uma defesa firme e uma alta muralha contra essa imensidade falante que se dirige a nós, desviando-nos de nós". ${ }^{23}$ Ruído, dispersão, desatenção. A literatura como antídoto a esse estado de coisas que tende a uma entropia progressiva.

Por fim, e para voltarmos à questão da imagem fotográfica, cumpre lembrar que também ela pode ser "lida" de uma maneira diferente, também numa perspectiva de resistência à percepção desatenciosa tão bem indiciada em "Rremembranças". 
Afinal, também ela faz do silêncio uma dimensão fundamental de sua existência, conforme esta bela reflexão de Baudrillard:

Sem que nos demos conta, é uma das qualidades mais preciosas e mais originais da imagem fotográfica, diferentemente do cinema, da televisão [...] Silêncio não somente da imagem que renuncia a qualquer discurso, para ser vista e lida de algum modo 'interiormente' - mas também o silêncio no qual mergulha o objeto que ela apreende. ${ }^{24}$

O texto de Valêncio Xavier sobre a menina assassinada atravessa diversas camadas de barulho para nos dizer ou pelo menos apontar esse silêncio (que se afina com o ato de rememoração).

Abstract: This article proposes an approach to relationships among photography, death and remembrance; to situate that reflection in the current context of mass media we perform the critical analyses of the text of fiction Rremembranças da Menina de Rua Morta Nua, work of Valêncio Xavier marked formally by the simultaneous use of words images.

Key-words: photography; mass Media; Valêncio Xavier.

\section{Referências}

BENJAMIN, Walter. Sobre o conceito da história. In: BENJAMIN, Walter. Magia e técnica, arte e política: ensaios sobre literatura e história da cultura. 7. ed., trad. Sérgio Paulo Rouanet, São Paulo: Brasiliense, 1994, p. 222-232. - (Obras escolhidas; v. 1)

AGAMBEN, Giorgio. "O Dia do Juízo”, in Profanações. Trad. Selvino José Assmann. São Paulo, Bo, 2007.

BARTHES, Roland. La Chambre Claire: Note sur La Photographie. Paris, Cahiers du Cinéma, Gallimard, Seuil, 1980.

BENJAMIN, Walter. "Crónica de Berlin", in Personages Alemanes. Trad. Luiz Martinez de Velasco. Barcelona, Ediciones Paidós, 1995.

CAMÕES, Luís de. Os Lusíadas. Introdução e notas de Alexei Bueno. Rio de Janeiro, Nova Fronteira, 1993.

GAGNEBIN, Jeanne Marie. História e Narração em Walter Benjamin. São Paulo, Perspectiva, 1999.

GAGNEBIN, Jeanne Marie. "O Hino, a Brisa e a Tempestade: Dos Anjos em Walter Benjamin”, in Sete Aulas sobre Linguagem, Memória e História. Rio de Janeiro, Imago, 1997.

KOSSOY, Boris. Origens e Expansão da Fotografia no Brasil - Século XIX. Rio de Janeiro, FUNARTE, 1980.

KOSSOY, Boris. Os Tempos da Fotografia: O Efêmero e o Perpétuo. São Paulo, Ateliê Editorial, 2007.

PERRONE-MOISÉS, Leyla. Altas Literaturas: Escolha e Valor na Obra Crítica de Escritores Modernos. São Paulo, Companhia das Letras, 1998.

PIGLIA, Ricardo. Formas Breves. Trad. José Marcos Mariani de Macedo. São Paulo, Companhia das Letras, 2004. 
SONTAG, Susan. Sobre Fotografia. Trad. Rubens Figueiredo. São Paulo, Companhia das Letras, 2004.

XAVIER, Valêncio. "Maciste no Inferno", in O Mez da Grippe e Outros Livros. São Paulo, Companhia das Letras, 1998.

XAVIER, Valêncio. "Rremembranças da Menina de Rua Morta Nua", in Rremembranças da Menina de Rua Morta Nua e Outros Livros. São Paulo, Companhia das Letras, 2006.

\section{Notas}

${ }^{1}$ SONTAG, Sobre Fotografia, p. 85.

${ }^{2}$ BARTHES, La Chambre Claire: Note sur La Photographie , p. 23.

${ }^{3}$ KOSSOY, Origens e Expansão da Fotografia no Brasil - Século XIX, p. 54-55.

${ }^{4}$ Idem, p. 54.

${ }^{5}$ AGAMBEN, “O Dia do Juízo”, p. 29.

${ }^{6}$ Idem, p. 30.

${ }^{7}$ Idem, p. 29.

${ }^{8}$ GAGNEBIN, "O Hino, a Brisa e a Tempestade: Dos Anjos em Walter Benjamin”, p. 135.

${ }^{9}$ BENJAMIN, "Crónica de Berlin", p. 71-72.

${ }^{10}$ GAGNEBIN, História e Narração em Walter Benjamin, p. 16. Tratando-se aqui de um volume especial em homenagem à Jeanne Marie Gagnebin, gostaria de deixar registrado que tive a honra e o prazer de acompanhar uma disciplina de pós-graduação ministrada pela professora em 1997 no IEL / Unicamp. A disciplina girava em torno da Escola de Frankfurt e foi uma grata surpresa em muitos sentidos. A lembrança mais marcante resulta da percepção, ainda naquele momento, de que as qualidades de profundidade, rigor e clareza de reflexão crítica que já conhecia de livros se repetiam oralmente em sala de aula. E ainda havia o bom humor de Jeanne Marie! Enfim, uma lembrança que se liga ao meu presente - para minha felicidade.

11 - XAVIER - Remembranças da Menina de Rua Morta Nua, p. 40.

12 XAVIER - Remembranças da Menina de Rua Morta Nua, p. 41.

${ }^{13}$ Idem, p.52.

${ }^{14}$ Cf. XAVIER, "Maciste no Inferno", p. 81-135.

${ }^{15}$ XAVIER - Remembranças da Menina de Rua Morta Nua, p. 49.

${ }^{16}$ XAVIER - Remembranças da Menina de Rua Morta Nua, p. 42.

${ }^{17}$ Idem, p. 44.

${ }^{18}$ Idem, p. 57.

${ }^{19}$ Idem, p. 42.

${ }^{20}$ Idem, p. 56.

${ }^{21}$ CAMÕES, Os Lusíadas, p. 135.

${ }^{22}$ PIGLIA, Formas Breves, p. 38.

${ }^{23}$ Apud PERRONE-MOISÉS, Altas Literaturas: Escolha e Valor na Obra Crítica de Escritores Modernos, p. 211.

${ }^{24}$ Apud Kossoy, Os Tempos da Fotografia: O Efêmero e o Perpétuo, p. 133) 